\title{
Sexual Dimorphism in the Tooth-Crown Diameters of the Deciduous Teeth
}

\author{
THOMAS K. BLACK III \\ Museum of Anthropology, The University of Michigan, Ann Arbor, Michigan 48109
}

\begin{abstract}
KEY WORDS Deciduous dentition - Sexual dimorphism - Discriminant function
\end{abstract}

\begin{abstract}
Mesiodistal and buccolingual crown dimensions of the right deciduous teeth of 133 white children were analyzed for information on sexual dimorphism and sex discrimination using discriminant analysis. Even though consistent differences were found for only 15 out of 20 paired measurements, five of them significant at $p=0.05$ or better, discriminant analysis showed the possibility of correctly sexing up to $75 \%$ of the juvenile sample, using a maximum of seven deciduous teeth.
\end{abstract}

Discriminant functions have become a widely used method for the sexual diagnosis of human skeletal remains (Pons, '55; Thieme and Schull, '57; Giles, '64, '66, '70; Giles and Elliot, '63; Van Vark, '70; Ditch and Rose, '72; Van Gerven, '72; Garn et al., '77). Recently, several investigators have had success with discriminant functions based on the toothcrown diameters of the permanent teeth alone (Ditch and Rose, '72; Garn et al., '77). Although these investigators did not discuss the obvious implications of their results for the sexual diagnosis of the remains of children, it is apparent that discriminant functions of the human dentition may provide reliable nonradiographic means for sexing immature skeletons.

The sexual identification of immature remains has been an important problem in physical anthropology for many years. Various workers have attempted to use size dimorphism in the dentition as an aid to sexing the remains of children. Bailit and Hunt ('64) achieved $58 \%$ accuracy by comparing the developmental ages of the individual dentitions with published male and female standards of tooth formation from radiographs. These authors assigned to the individual the sex of the standard which caused the least variation among teeth. The discriminant functions employed by Ditch and Rose ('72) and Garn et al. (77) improved the accuracy of sexing of older children to $85 \%$ or better. However, their dis- criminant functions were based on the permanent teeth and would sex few children less than 12 years of age. If sexual dimorphism in tooth-crown size is as pronounced in the deciduous dentition as it is in the permanent dentition, then it may be possible to correctly assess the sex of children as young as two years.

Percent sexual dimorphism between the male and female means for the dental measurements is presented together with tests for the significance of the differences of the means. Five sets of discriminant functions are calculated to determine the most reliable combination of measurements for sexing the deciduous dentition. One set of discriminant functions is based on the 20 dental measurements used in this paper, the other four sets of functions include only ten measurements each; these four sets are the maxillary teeth, the mandibular teeth, all mesiodistal measurements, and all buccolingual measurements.

\section{MATERIALS AND METHODS}

The mesiodistal and buccolingual diameters of the right deciduous teeth of 69 boys and 64 girls in the University School Growth Study of the University of Michigan were chosen for study. These individuals were selected from the sample of 204 white children used by Garn et al. (77) because they had a complete set of measurements (10 mesiodistal, 10 buccolin- 
TABLE 1

Percent of sexual dimorphism and significance of mean differences in male and female deciduous tooth size ${ }^{1.2}$

\begin{tabular}{|c|c|c|c|c|c|c|}
\hline & \multicolumn{2}{|c|}{69 males } & \multicolumn{2}{|c|}{64 females } & \multirow{2}{*}{$\begin{array}{c}\text { Percent } \\
\text { dimorphism }\end{array}$} & \multirow[b]{2}{*}{$t$} \\
\hline & Mean & S.D. & Mean & S.D. & & \\
\hline \multicolumn{7}{|c|}{ Mesodistal } \\
\hline $\mathrm{i}^{1}$ & 6.40 & 0.443 & 6.52 & 0.360 & -1.84 & -1.76 \\
\hline $\mathrm{i}^{2}$ & 5.24 & 0.372 & 5.33 & 0.392 & -1.69 & -1.37 \\
\hline Max.c & 6.78 & 0.375 & 6.66 & 0.355 & 1.80 & 1.89 \\
\hline $\mathrm{m}^{1}$ & 6.69 & 0.474 & 6.59 & 0.465 & 1.52 & 1.16 \\
\hline $\mathrm{m}^{2}$ & 8.84 & 0.616 & 8.79 & 0.468 & 0.57 & 0.51 \\
\hline$i_{1}$ & 4.03 & 0.335 & 4.10 & 0.309 & -1.71 & -1.25 \\
\hline$i_{2}$ & 4.58 & 0.431 & 4.72 & 0.386 & -2.97 & -1.90 \\
\hline Mand. c. & 5.83 & 0.337 & 5.81 & 0.262 & 0.34 & 0.31 \\
\hline $\mathrm{m}_{1}$ & 7.85 & 0.443 & 7.74 & 0.403 & 1.42 & 1.44 \\
\hline $\mathrm{m}_{2}$ & 9.88 & 0.482 & 9.69 & 0.548 & 1.96 & $2.14^{3}$ \\
\hline \multicolumn{7}{|c|}{ Buecolingual } \\
\hline$i^{1}$ & 5.13 & 0.430 & $5.19^{\circ}$ & 0.482 & -1.16 & -0.71 \\
\hline$i^{2}$ & 4.71 & 0.396 & 4.64 & 0.388 & 1.51 & 0.96 \\
\hline Max.c & 6.11 & 0.396 & 5.97 & 0.414 & 2.34 & $1.98^{3}$ \\
\hline $\mathbf{m}^{1}$ & 8.83 & 0.497 & 8.56 & 0.550 & 3.15 & $2.98^{4}$ \\
\hline $\mathrm{m}^{2}$ & 9.54 & 0.492 & 9.36 & 0.450 & 1.92 & $2.19^{3}$ \\
\hline$i_{1}$ & 3.86 & 0.382 & 3.84 & 0.348 & 0.52 & 0.20 \\
\hline$i_{2}$ & 4.37 & 0.376 & 4.35 & 0.280 & 0.46 & 0.39 \\
\hline Mand. c & 5.60 & 0.307 & 5.55 & 0.401 & 0.90 & 0.86 \\
\hline $\mathrm{m}_{1}$ & 7.37 & 0.484 & 7.31 & 0.443 & 0.82 & 0.70 \\
\hline $\mathrm{m}_{z}$ & 8.90 & 0.396 & 8.70 & 0.432 & 2.30 & $2.83^{4}$ \\
\hline \multicolumn{5}{|c|}{ Mean absolute value of percent dimorphism } & 1.54 & \\
\hline
\end{tabular}

'Percent sexual dimorphism is computed by the formula: 100 (male mean/female mean) -100

2 All measurements are in millimeters.

${ }^{3} \mathrm{p} \leqslant 0.05 ;{ }^{4} \mathrm{p} \leqslant 0.01$.

gual) for the deciduous teeth of the right side of the dental arch. Using this subsample of 133 children with complete sets of measurements insured that the sample size would not change between discriminant functions incorporating different sets of measurements.

The dental dimensions were measured on an optical digitizing device, the OPTOCOM (Van der Linden et al., '72; Moyers et al., '76). The measurements from multiple casts of each individual were averaged, and the resulting raw values were examined for sex-based differences with univariate and multivariate analyses employing the Michigan Interactive Data Analysis System (MIDAS).

Student's $t$ was used to test the difference between the male and female means for each of the 20 measurements. Percent sexual dimorphism $(100 \times$ [male mean/female mean]100) was also calculated for each measurement. These two univariate analyses helped focus attention on those individual measurements showing a large degree of sexual dimorphism.

Five sets of variables were then included in stepwise discriminant analyses (Afifi and Azen, '72) using statistical procedures incor- porated into MIDAS. These analyses were employed to isolate combinations of variables which most effectively separate the sexes. The sets of variables used for each discriminant analysis were selected so that the accuracy of sexual discrimination for different sets of teeth and measurements could be contrasted. The total of 20 variables was kept intact for one set of stepwise discriminant functions and was subdivided for the other four into ten mesiodistal, ten buccolingual, ten maxillary, and ten mandibular variables. The selection of variables is of practical interest to the physical anthropologist dealing with archaeological materials, as either the mandible or the maxilla is often missing from excavated material. In these circumstances, discriminant functions combining measurements from both jaws would be of no use. Furthermore, because the mesiodistal crown diameters of the teeth are reduced by interproximal wear, the buccolingual measurements may prove more useful for sex identification.

\section{RESULTS}

In all, the teeth of boys tend to be larger than those of girls in 15 of 20 comparisons 


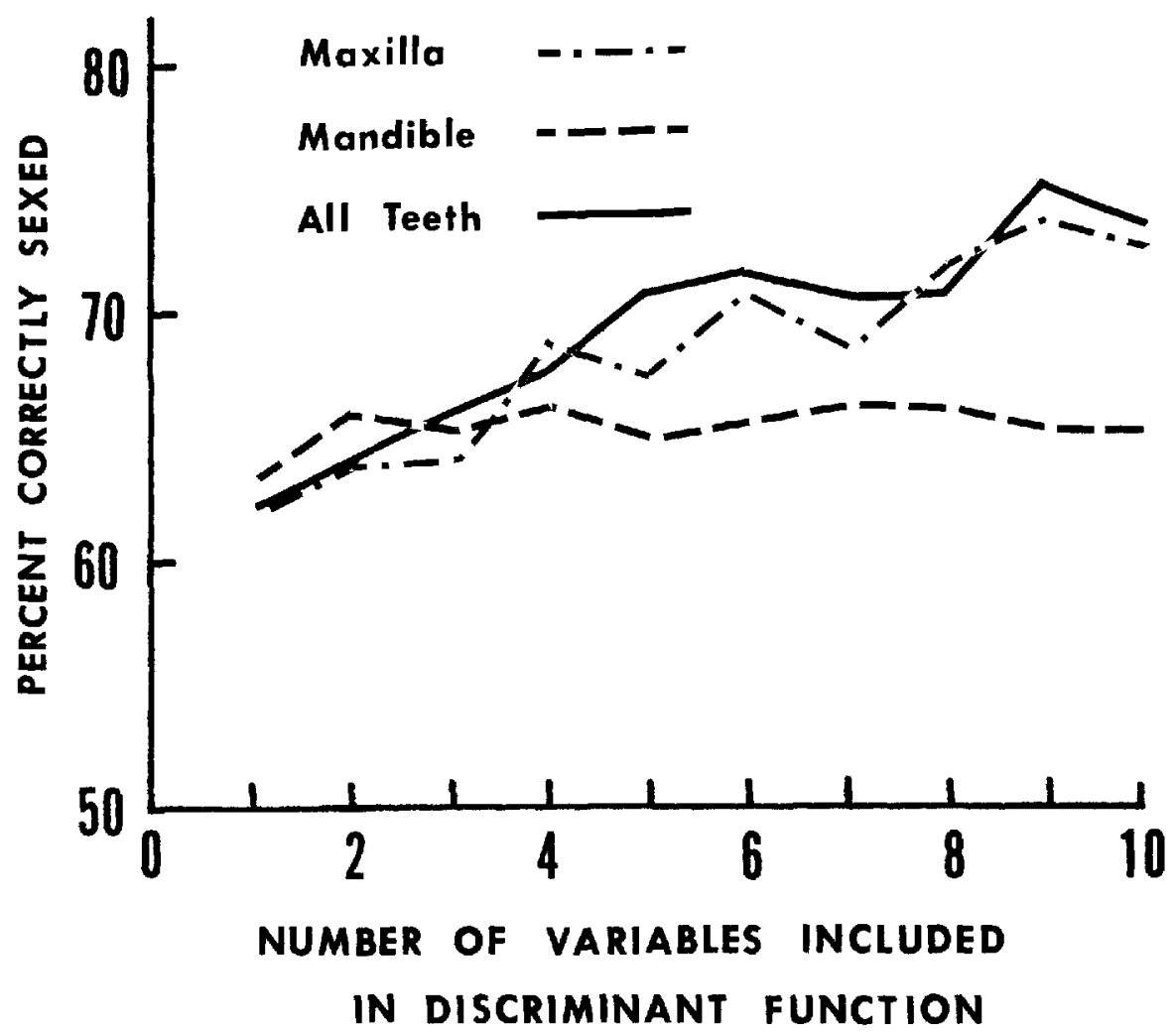

Fig. 1 Percentages of the 133 individuals correctly sexed by stepwise discriminant functions based on measurements of the maxillary teeth alone, the mandibular teeth alone, and all teeth together.

(table 1). A sign test shows that the 1-tailed probability of the 15:5 distribution occurring as a chance deviation from the expected 10:10 distribution is $p=0.021$. For five measurements the female mean exceeds the male mean: the lengths of all four incisors and the breadth of the upper central incisor. These results are contrary to those of Moorrees et al. ('57) who found that the male mean mesiodistal diameter exceeded the female mean for all the deciduous teeth.

Student's $t$ showed that the means of five variables are significantly dimorphic at the $p \leqslant 0.05$ level, whereas only one significant difference would be expected by change. The male mean significantly exceeds the female mean in the mesiodistal diameter of $m_{2}$ and the buccolingual diameters of $\mathrm{m}_{2}, \mathrm{~m}^{\mathrm{I}}, \mathrm{m}^{2}$, and the maxillary canine.

In the other univariate analysis, four teeth show sexual dimorphism greater than $2.0 \%$. The male exceeds the female mean on three of them: the widths of the upper canine, the upper first molar, and the lower second molar; the female mean exceeds the male mean for the length of the lower lateral incisor. The greatest percent dimorphism in the deciduous dentition is $3.15 \%$ for the buccolingual diameter of $\mathrm{m}^{1}$.

The stepwise discriminant functions began with no variables included in the model, then added the variable with the largest value for its F-statistic, which measures the ratio of within sex variance to total generalized variance. The stepwise discriminant functions proceeded through the allotted variables for each model in this manner, adding one variable at each step, and computing a new discriminant function for each step. For the set of 20 variables, this resulted in 20 discriminant functions including from 1 to 20 variables. The smaller sets of variables had ten discriminant functions each. The percent of the total sample correctly classified by each of the ten stepwise discriminant functions for the maxillary, mandibular, mesiodistal, and buc- 


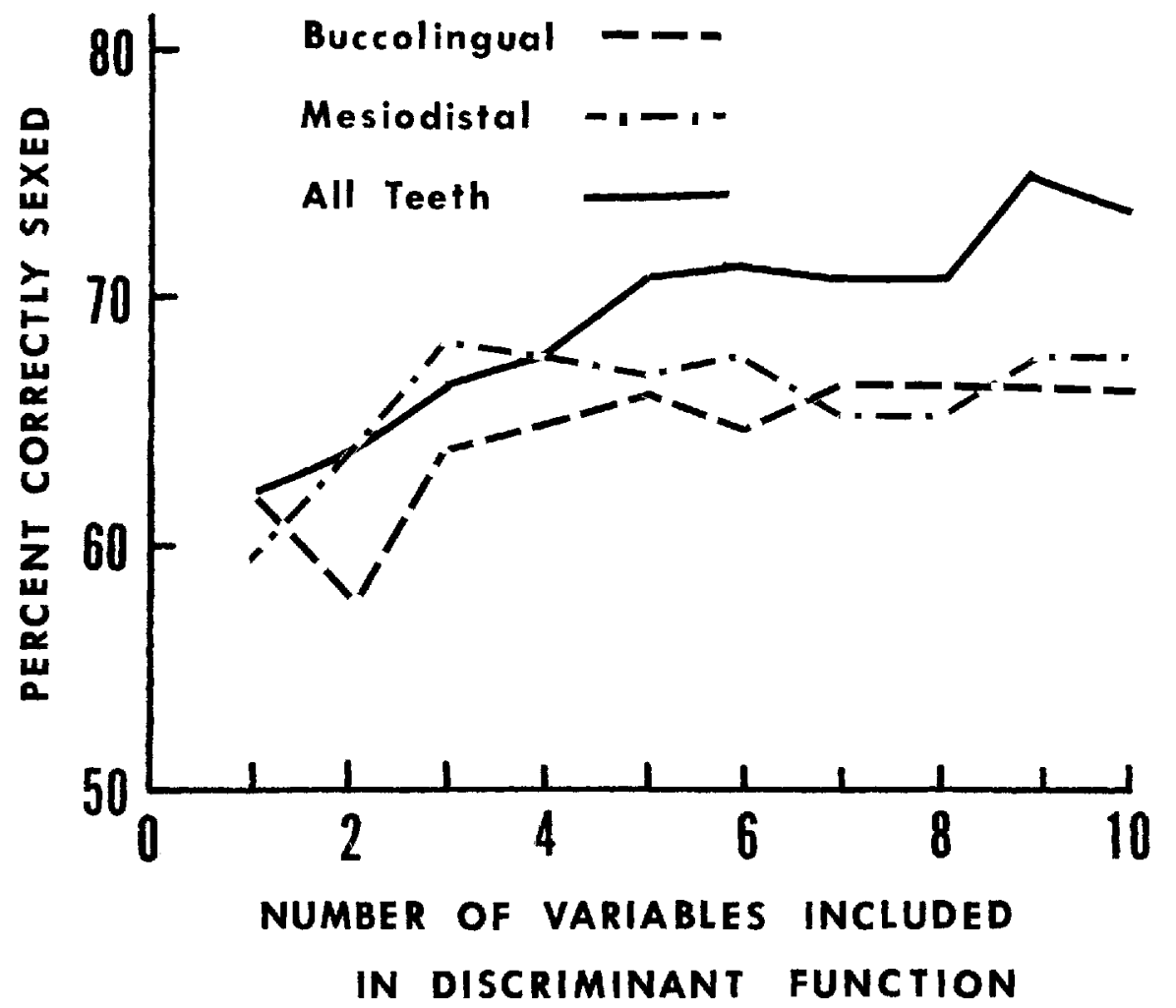

Fig. 2 Percentages of the 133 individuals correctly sexed by stepwise discriminant functions based on all the teeth, employing mesiodistal measurements alone, buccolingual measurements alone, and both measurements together.

TABLE 2

Discriminant functions for sexing the deciduous dentition ${ }^{1}$

\begin{tabular}{|c|c|c|c|}
\hline \multirow{2}{*}{ Functions } & \multicolumn{3}{|c|}{$\begin{array}{c}\text { Percent } \\
\text { correctly classified }\end{array}$} \\
\hline & Male & Female & Total \\
\hline $\begin{array}{l}\text { 1. Function using the maxillary teeth alone: } \\
-2.91+1.512\left(\mathrm{~m}^{\prime} \mathrm{b}-1\right)-1.585\left(\mathrm{i}^{1} \mathrm{~m}-\mathrm{d}\right)\end{array}$ & 69.6 & 57.8 & 63.9 \\
\hline $\begin{array}{l}\text { 2. Functions using the mandibular teeth alone: } \\
-8.66+1.792\left(\mathrm{~m}_{2} \mathrm{~b}-1\right)-1.528\left(\mathrm{i}_{2} \mathrm{~m}-\mathrm{d}\right) \\
\text { 3. Function using mesiodistal measurements alone: } \\
-7.64+1.096\left(\mathrm{~m}_{2} \mathrm{~m}-\mathrm{d}\right)-1.976\left(\mathrm{i}^{1} \mathrm{~m}-\mathrm{d}\right)+\end{array}$ & 69.6 & 62.5 & 66.2 \\
\hline $\begin{array}{l}1.439(\max . \mathrm{cm}-\mathrm{d}) \\
\text { 4. Function using buccolingual measurements alone: } \\
-11.10+2.192\left(\mathrm{~m}^{\prime} \mathrm{b}-1\right)-1.924\left(\mathrm{~m}_{\mathrm{t}} \mathrm{b}-1\right)+ \\
1.311\left(\mathrm{~m}_{2} \mathrm{~b}-1\right)-1.042\left(\mathrm{i}^{1} \mathrm{~b}-1\right)\end{array}$ & 68.1 & 68.8 & 68.4 \\
\hline $\begin{array}{l}\text { 5. Function using mesiodistal and buccolingual measure- } \\
\text { ments of the maxillary and mandibular teeth: } \\
-8.18+2.343\left(\mathrm{~m}^{1} \mathrm{~b}-1\right)-2.192\left(\mathrm{i}^{1} \mathrm{~m}-\mathrm{d}\right)+ \\
2.046\left(\mathrm{~m}_{2} \mathrm{~b}-1\right)-2.187\left(\mathrm{~m}_{\mathrm{l}} \mathrm{b}-1\right)\end{array}$ & 72.5 & 62.5 & 67.7 \\
\hline
\end{tabular}

'Only variables with an F-statistic significant at $p \leqslant 0.05$ are included in the functions. The critical value for each of these functions is 0.0 . Individuals with a score greater than 0.0 are classified as males; those with a score less than 0.0 are classified as females. 
colingual variable sets is compared to the first ten stepwise functions calculated for the 20 . variable set (figs. 1,2 ).

In practice, it is seldom desirable to include every variable from a list of measurements with as high a degree of intercorrelation as dental dimensions. Adding highly correlated variables to a discriminant function may produce no new information to improve the discrimination and may actually introduce noise to reduce the discrimination. The problem with "noise" can be avoided if an F-statistic with a significance of $p \leqslant 0.05$ is required for the inclusion of a variable in a stepwise discriminant function. This cut-off point seems justified since few of the models increased their accuracy of sexing with the inclusion of less significant variables. No model included more than four significant variables.

Given the $p \leqslant 0.05$ criterion, the model based on the maxillary dentition includes the width of $\mathrm{m}^{1}$ (table 2). The mandibular model includes the width of $m_{2}$ and the length of $i_{2}$. The model based on mesiodistal measurements includes the lengths of $\mathrm{m}_{2}, \mathrm{i}^{1}$, and the upper canine. The model employing buccolingual measurements includes the widths of $\mathrm{m}^{1}, \mathrm{~m}_{1}, \mathrm{~m}_{2}$, and $\mathrm{i}^{1}$. The model based on all 20 variables includes the width of $\mathrm{m}^{1}$, the length of $i^{1}$, the width of $m_{2}$, and the width of $m_{1}$. The percentages of the population correctly sexed by the discriminant models incorporating these variables are $63.9,66.2,68.4,64.7$, and 67.7 , respectively. However, if the $p \leqslant 0.05$ criterion is ignored, then combinations of variables may correctly sex as much as $75.2 \%$ of the population.

\section{DISCUSSION}

Several of the variables with significant values for Student's $t$ were not included by the computer as significant variables in the stepwise discriminant analyses. This omission is probably due to the fact that these variables were quite highly correlated with variables already incorporated in the models so that their sex-related variability was redundant and contributed little to increasing the accuracy of the separation of sexes. Van Gerven ('72) noted a similar effect in his investigation of sexual dimorphism in the human femur.

The sexual dimorphism of the deciduous dentition is small compared to that of the permanent dentition. The mean of the absolute values of percent dimorphism for the deciduous teeth is less than the mean values for percent dimorphism of the mesiodistal toothcrown diameters of nine populations discussed by Garn et al. ('67). This effect is not due to the pooling of the buccolingual and mesiodistal dimorphism for the children, since the buccolingual dimorphism is comparable to the mesiodistal dimorphism for both children (this study) and adults (Garn et al., '66).

The relatively small degree of tooth-crown size dimorphism in the deciduous dentition makes the discriminant functions computed from these dimensions less effective for separating the sexes than similar discriminant functions calculated from the permanent dentition. The only discriminant model based on the deciduous dentition correctly sexing over $75 \%$ of the population required nine measurements on seven teeth. In comparison, two of the models presented by Garn et al. ('77) required only two measurements on the permanent dentition to sex 204 individuals (including the 133 examined for this study) with an accuracy exceeding $80 \%$.

Sexual dimorphism in tooth-crown diameters appears to be less pronounced in the deciduous than in the permanent dentition. The results of this study may be tempered by the observation that the population studied here is a statistical population, and the pattern and degree of dimorphism may be different than would be encountered in a biological population. Furthermore, the results reported here relate to the study population alone and should not be generalized beyond it.

\section{ACKNOWLEDGMENTS}

This study was supported in part by Grant DE 03610 from the National Institute of Health. The author thanks P. E. Cole and K. E. Guire of the Center for the Study of Human Growth and Development of the University of Michigan for their advice and information regarding the data. Gratitude is also extended to Doctor C. S. Peebles of the Museum of Anthropology and Doctor S. M. Garn of the Center for the Study of Human Growth and Development for their critical comments on earlier drafts of this paper. Doctor R. E. Moyers, Director of the Center for the Study of Human Growth and Development, is thanked for giving permission to use data he collected for this study. 


\section{LITERATURE CITED}

Afifi, A. A., and S. P. Azen 1972 Statistical Analysis: A Computer Oriented Approach. Academic Press, New York.

Bailit, H., and E. E. Hunt, Jr. 1964 The sexing of children's skeletons from teeth alone and its genetic implications. Am. J. Phys. Anthrop., 22: 171-174.

Ditch, L. E., and J. C. Rose 1972 A multivariate dental sexing technique. Am. J. Phys. Anthrop., 37: 61-64.

Garn, S. M., P. E. Cole, R. L. Wainwright and K. E. Guire 1977 Sex discrimination effectiveness using combinations of permanent teeth. J. Dent. Research, 56: 697 .

Garn, S. M., A. B. Lewis and R. S. Kerewsky 1966 Sexual dimorphism in the buccolingual tooth diameter. J. Dent. Research, 45: 1819.

Garn, S. M., A. B. Lewis, D. R. Swindler and R. S. Kerewsky 1967 Genetic control of sexual dimorphism in tooth size. J. Dent. Research, 46: $963-972$.

Giles, E. 1964 Sex determination by discriminant function analysis of the mandible. Am. J. Phys. Anthrop., 22: 129-136.

1966 Statistical techniques for sex and race determination: some comments in defense. Am. J. Phys. Anthrop., 25: 85-86.

1970 Discriminant function sexing of the human skeleton. In: Personal Identification in Mass Disas- ters. T. T. Stewart, ed. Smithsonian Institution, Washington, D.C., pp. 99-109.

Giles, E., and O. Elliot 1963 Sex determination by discriminant function analysis of crania. Am. J. Phys. Anthrop., 21: 53-68.

Moorees, C. F. A., S. Ø. Thomsen, E. Jensen and P. K. Yen 1957 Mesodistal crown diameters of the deciduous and permanent teeth in individuals. J. Dent. Research, 36: 39-46.

Moyers, R. E., F. P. G. M. Van der Linden, M. L. Riolo and J. A. McNamara, Jr. 1976 Standards of Human Occlusal Development. University of Michigan, Ann Arbor, Michigan.

Pons, F. 1955 The sexual diagnosis of isolated bones of the skeleton. Hum. Biol., 27; 12-21.

Thieme, F. P., and W. F. Schull 1957 Sex determination of the skeleton. Hum. Biol., 29: 242-273.

Van der Linden, F. P. G. M., H. Boersma, T. Zelders, F. A. Peters and J. H. Raaben 1972 Three-dimensional analy. sis of dental casts by means of the Optocom. J. Dent. Re. search, 51: 1100 .

Van Gerven, D. P. 1972 The contribution of size and shape variation to patterns of sexual dimorphism of the human femur. Am. J. Phys. Anthrop., 37: 49-60.

Van Vark, G. N. 1970 Some Statistical Procedures for the Investigation of Prehistoric Human Skeletal Mate rial. V. R. B. Offsetdrukkerij, Groningen, The Netherlands. 